\title{
Artigo
}

\section{As intuições matemáticas primordiais}

\author{
Pablo Rwany Batista Ribeiro do Vale* (iD \\ Walter Melo
}

\author{
Universidade Federal de Juiz de Fora, Juiz de Fora, MG, Brasil \\ Universidade Federal de São João del-Rei, São João del-Rei, MG, Brasil
}

\begin{abstract}
Resumo: Este artigo apresenta um estudo exploratório sobre os aspectos quantitativos e qualitativos do número na obra de Jung. Assim, foi efetuado levantamento de aspectos do número, desde os testes de associação de palavras até o conceito de sincronicidade. $\mathrm{O}$ artigo foi dividido em três partes: apresentação de aspectos quantitativos (tempo de reação no teste de associação de palavras e conceito de energia psíquica); apresentação de aspectos qualitativos (número como conteúdo psíquico, número como elemento organizador da psique, caráter numinoso do número, número como grandeza imprevisível entre mito e realidade, a relação do número com os eventos sincronísticos e o número como arquétipo da ordem que se tornou consciente); e apresentação das intuições matemáticas primordiais (a série infinita de números naturais e a ideia de continuum). Ao enfatizar os aspectos qualitativos, Jung aponta para a base arquetípica do número como fator de ordenação e de articulação entre psique e matéria.
\end{abstract}

Palavras-chave: C. G. Jung, psicologia analítica, número, arquétipo.

\section{Introdução}

Podemos pensar a Psicologia Analítica como um campo de conhecimento em diálogo. Nesse sentido, Jung empreendeu debates com pesquisadores de várias áreas. A partir de seu campo de trabalho, dirigiu a atenção a fenômenos religiosos, míticos, antropológicos, artísticos, pré-científicos - como a alquimia - e das diversas transformações da ciência de seu tempo, notadamente da física. Com isso, não pretendia, em hipótese alguma, romper com a ciência e se aventurar em concepções metafísicas (Jung, 1935/2011). A observação de fenômenos anômalos (Kuhn, 1962/2007) possibilitou que o escopo científico fosse alargado, levando-o às margens do conhecimento psicológico (Melo, 2015, 2019).

As Conferências de Eranos são, nesse sentido, exemplares. Organizadas por Olga Fröbe-Kapteyn, a partir de 1933, e com nome sugerido por Rudolf Otto banquete compartilhado ou troca de alimentos -, tinha como princípio o intenso debate interdisciplinar (Ferreira \& Silveira, 2015). Jung participou dos encontros de Eranos, de maneira efetiva, de 1933 a 1951, proferindo catorze palestras (Quaglino, Romano, \& Bernardini, 2007). Cabe, neste estudo, destacar o encontro de Eranos de 1940, que teve como tema geral o simbolismo da trindade. A princípio, a única palestra daquele ano seria do matemático Andreas Speiser, intitulada "A doutrina platônica do Deus desconhecido e a trindade cristã". Jung escutou atentamente a palestra e, ao final, solicitou uma Bíblia à anfitriã, fez algumas anotações à sombra de uma árvore e, como uma

*Endereço para correspondência: psipablodovale@gmail.com resposta a Speiser, apresentou a palestra "Uma abordagem psicológica do Dogma da Trindade” (Jaffé, 1989).

A palestra em Eranos aconteceu em meio ao intenso diálogo interdisciplinar estabelecido entre Jung e o físico Wolfgang Pauli. A troca de conhecimentos entre os dois pensadores é bastante significativa do processo de refinamento sobre os aspectos quantitativos e qualitativos do número e da mensuração, levando à ampliação do escopo científico. Podemos acompanhar esse diálogo em diversos livros, artigos e cartas (Jung, 1939/2011, 1944/2011, 1946/2011e, 1950/2011c; Meier, 1992/2011; Miller, 2009; Pauli, 1952/1996). Um dos pontos mais importantes dessa interlocução diz respeito à base arquetípica para as concepções teóricas. Dessa maneira, os dois autores estabelecem as condições necessárias para pensar a relação entre psique e matéria, tendo como parâmetro a noção de arquétipo.

A partir do diálogo de Jung com Pauli, o conceito de arquétipo ganha nova conotação. De um ponto de vista estritamente psicológico, o arquétipo não pode ser observado de maneira direta, mas por meio das imagens psíquicas, de caráter coletivo, ou seja, arquetípicas (Jung, 1944/2011). Sem contradizer esse aspecto, a partir dos estudos acerca dos fenômenos de sincronicidade, podem ocorrer, de maneira acausal, processos físicos equivalentes aos psíquicos (Jung, 1950/2011c). Nessa interação entre as realidades física e psíquica, Pauli afirma que os aspectos quantitativos e qualitativos devem ser reconhecidos simultaneamente e, nesse sentido, é fundamental a análise do número como "a intuição matemática primordial"

1 No original: "l'intuition mathématique primordiale". 
(Pauli, 1955/1999, p. 193, tradução nossa), como a noção de infinito presente na série de números naturais (aritmética) e na ideia de continuum (geometria).

Os números se caracterizam como elementos que possibilitam a quantificação. Assim, podemos ordenar o mundo por meio dos números. Mas, como se tratam de conteúdos psicológicos, apresentam também aspectos qualitativos. Nesse sentido, possibilitam a contagem e a medida de aspectos da realidade concreta (quantitativo), mas, por outro lado, dizem respeito a conteúdos psíquicos, de cunho imaginário (qualitativo) (Jung, 1954/2011). O ordenamento não é, portanto, limitado ao simples enumerar, sendo responsável por inserir o sujeito na relação de produzir e apreender a ordem do mundo, implicando em aspectos quantitativos e qualitativos da enumeração que se complementam (Franz, 1970/2012; Jung, 1950/2011c).

Levando em consideração esses argumentos iniciais, dividimos este artigo em três partes com subdivisões, sendo a primeira concernente à apresentação de alguns aspectos quantitativos do número e da mensuração na obra de Jung referentes, portanto, ao tempo de reação no teste de associação de palavras e o conceito de energia psíquica. A segunda parte trata da apresentação de alguns aspectos qualitativos do número e da mensuração na obra de Jung, sendo esses: o número como conteúdo psíquico, o número como elemento organizador da psique - abrangendo também o caráter compensatório do campo inconsciente e a estrutura das mandalas -, o caráter numinoso do número, a grandeza divina, a relação entre a trindade e a quaternidade, o número como grandeza imprevisível entre o mito e a realidade, a relação do número com os eventos sincronísticos e o número como arquétipo da ordem que se tornou consciente. A terceira e última parte trata sobre a apresentação das denominadas intuições matemáticas primordiais, que são a série infinita de números naturais e a ideia de continuum. Dessa maneira, prezamos pela disponibilidade em mantermos o debate interdisciplinar e pela superação do monismo metodológico (Feyerabend, 1975/2011).

\section{Aspectos quantitativos do número e da mensuração}

Na obra de Jung, os aspectos quantitativos do número e da mensuração são abordados, principalmente, em dois livros: Estudos Experimentais (1905/2011) e A Energia Psíquica (1928/2011). Nesses dois casos, temos os aspectos quantitativos como maneira de compreender a fenomenologia dos complexos de tonalidade afetiva e da energia psíquica, respectivamente, por meio de instrumentos de medida e de relações de movimento. No teste de associação de palavras, o que se espera é especificar atributos suscetíveis de mensuração (Jung, 1979/2011). A magnitude de determinado objeto é denominada pelo termo mensurando e, para estabelecer seu valor, é necessário utilizar métodos adequados de medida (Piacentini, Grandi, Hufmann, Lima, \& Zimmermann, 2008). E, no caso da energia psíquica, a mensuração está diretamente relacionada à força apresentada pelo núcleo do complexo, à frequência e intensidade dos complexos, e à intensidade dos afetos (Jung, 1928/2011).

\section{O tempo de reação no teste de associação de palavras}

Em seus estudos com o teste de associação, Jung (1905/2011) parte de palavras indutoras para as quais o sujeito do experimento deve reagir com uma palavra resposta. $\mathrm{O}$ intervalo entre a enunciação da palavraestímulo e a reação verbal do sujeito do experimento é denominado tempo de reação, considerado, por si só, um importante fator a ser analisado no experimento. No entanto Jung observa outras variáveis que interferem no tempo de reação, pois, nesse intervalo, a pessoa pode ficar enrubescida, tremer, gaguejar, suar etc. Assim, à mensuração do tempo de resposta são associados outros aspectos emocionais, evidenciados em alterações físicas. Os componentes do tempo de reação são medidos e analisados. Além desses dados, as medições do pulso e do batimento cardíaco também são levadas em consideração.

O instrumento utilizado por Jung (1905/2011) durante o teste de associação de palavras é o relógio de $1 / 5$ de segundo, considerando-o satisfatório para a medição do tempo em experimentos de associações sucessivas. Além de medir cada reação, é efetuada a média entre todos os tempos de resposta. Não se trata, porém, de uma simples média aritmética, pois considera que os tempos de resposta, muitas vezes, são excessivamente longos, influenciando na análise do experimento:

Este inconveniente pode ser evitado pelo emprego do método da média provável que consiste em ordenar em série os números de acordo com seu valor e tomar o número mais próximo do meio. Assim fica eliminada a influência de valores excessivamente altos. (p. 253)

Nesse contexto, o número é um ordenador de dados, um mensurador, ou seja, cumpre uma função estritamente quantitativa. Essa preocupação em quantificar não significa, no entanto, a busca por médias absolutas, mas valores médios aproximados que criem uma base para a compreensão dos processos patológicos. Os trabalhos experimentais de Jung apresentam a primazia dos aspectos quantitativos do número, visando ordenar e mensurar dados no âmbito da psiquiatria (Jung, 1905/2011).

\section{O conceito de energia psíquica}

De acordo com Jung (1928/2011), Wundt aborda os fenômenos físicos a partir de dois modelos: mecanicista e energético. O teste de associação de palavras é de cunho 
mecanicista, pois "compreende o fenômeno como sendo o efeito resultante de uma causa" (p. 13). O ponto de vista energético, por outro lado, é de caráter finalista, ou seja, os fenômenos são entendidos do efeito para a causa. Isso significa que, na raiz das mudanças ocorridas em dado fenômeno, há uma energia mantida em constância, produzindo, de maneira entrópica, um estado geral de equilíbrio no âmago dessas mutações.

A dinâmica do processo energético tem uma direção definida que obedece categoricamente a diferença de potencial: "A ideia de energia não é de uma substância que se movimenta no espaço, mas um conceito abstraído das relações de movimento" (Jung, 1928/2011, p. 14). Nessa mesma linha de raciocínio, o físico Paul G. Hewitt (2011) afirma que, apesar de familiar, é difícil definir a energia, pois: "Observamos a energia nas coisas apenas quando ela está sendo transferida ou transformada" (p. 104).

Nessa relação de movimento, a observação da energia em processo de transferência ou de transformação, há a possibilidade de abordar o fenômeno pelo viés quantitativo. Assim, Jung (1928/2011) argumenta que "não há motivos para excluir o acontecimento psíquico do campo dos dados objetivos da experiência" (p. 16). Então, partindo do princípio de que a energia é um fator mensurável e que é possível verificar o aspecto quantitativo da energia psíquica, Jung define a psique como um "sistema energético relativamente fechado" (p. 18). Mas como mensurar a quantidade de energia psíquica?

Como a abordagem energética está vinculada a avaliações quantitativas e não diz respeito às substâncias em si, mas às relações que estabelecem, Jung (1928/2011) observa que a energia psíquica necessita de parâmetros para uma avaliação quantitativa objetiva. Nesse ponto, algumas considerações acerca do complexo de tonalidade afetiva são importantes: o complexo possui um núcleo e, ao redor dele, são agrupadas associações secundárias; o núcleo tem um fator relacionado a experiências vividas e outro fator imanente ao indivíduo; a principal característica do núcleo é apresentar afetos acentuados. Assim, do ponto de vista energético, a tonalidade afetiva é "uma quantidade de valor" (p. 21).

A mensuração dessa quantidade de afeto deve levar em consideração, portanto, a força aglutinadora do núcleo do complexo. Essa força consteladora é diretamente proporcional ao seu valor energético. A quantidade de energia psíquica pode ser estimada a partir de três aspectos: (1) pelo número relativo de constelações, ou seja, a tendência é de quanto maior a cadeia de ideias associadas ao núcleo do complexo também ser maior o valor psicológico; (2) pela frequência e intensidade que os complexos causam perturbações; (3) pela intensidade de outros fatores afetivos, que podem ser verificados através da curva do pulso, da curva respiratória e de fenômenos psicogalvânicos (Jung, 1928/2011; Peterson \& Jung, 1907/2011; Ricksher \& Jung, 1907/2011).

\section{Aspectos qualitativos do número e da mensuração}

Jung (1979/2011) observa que os dois pontos de vista - quantitativo e qualitativo - têm seus méritos. Apoiado nas concepções de Jung, o físico Wolfgang Pauli se contrapõe aos pressupostos da ciência ocidental moderna, que alia a indução empírica ao pensamento lógico-matemático. Pauli afirma que, na primeira metade do século XVII, a nova forma de fazer ciência (matemática e quantitativa), que desembocou no pensamento moderno, colide com, por exemplo, a tradição alquímica (de imagens simbólicas e qualitativas). Essa cisão entre quantitativo e qualitativo foi revisitada no diálogo estabelecido entre Jung e Pauli, notadamente através dos arquétipos, "enquanto operadores de ordem e formadores de imagens" (Pauli, 1952/1996, p. 280, tradução nossa).

A posição defendida por Jung está, muitas vezes, associada à retomada e à resistência romântica diante do cientificismo (Bishop, 2007). Nesse caso, há uma tendência de alinhamento da Psicologia Analítica ao "eixo axiológico romântico . . . sempre de índole restauradora" (Figueiredo, 2015, p. 88). As reflexões de Jung podem ser vistas, no entanto, como um modo de aliar o rigor científico à vertente romântica (Wahba, 2019). Essa segunda posição nos faz pensar a Psicologia Analítica como proposta que cultiva o universalismo romântico como método (Duarte, 1999). A proposta advinda dos diálogos entre Jung e Pauli pretende a aliança entre as duas posições - cientificistas e românticas - que priorizam, respectivamente, os aspectos quantitativos e qualitativos do número e da mensuração.

\section{O número como conteúdo psíquico}

Marie-Louise von Franz (1980/1985) reafirma a ideia de que os números apresentam aspectos quantitativos e qualitativos. Como conteúdos psíquicos, os números podem surgir em sonhos, pensamentos, fantasias e, também, na produção de conhecimento no campo da matemática. No último caso, há a dupla função apontada por Pauli (1952/1996), de ordenação dos fenômenos empíricos e de ordenação dos fenômenos psíquicos, com as imagens psíquicas funcionando como fundamento arquetípico (aspecto qualitativo) para as elaborações matemáticas (aspecto quantitativo). Nos demais exemplos, o número se apresenta apenas como imagem psíquica de base arquetípica, como símbolo, portanto, em seu aspecto qualitativo (Vale \& Melo, 2019). No entanto mesmo matemáticos reconhecem que o número tem aspectos irracionais, sendo muito mais que um simples e compreensível elemento de mensuração (Kasner \& Newman, 1968).

2 No original: "en tanto que operadores de orden y formadores de imágenes". 
Ainda em seu período psicanalítico, Jung (1910/2011) conferiu importância ao número como imagem simbólica, analisando o sonho de um homem de meia idade, tendo o número de um bilhete de trem como elemento central. Mas, além do aparecimento do número em uma manifestação psicológica, podemos perceber o número como conteúdo psíquico que está correlacionado aos demais aspectos apresentados nesta seção: organizador da psique, caráter numinoso, grandeza imprevisível, eventos sincronísticos e arquétipo da ordem.

\section{O número como elemento organizador da psique}

A psique se organiza, de acordo com Jung (1921/2011; 1944/2011, 1950/2011b, 1961/2008), a partir de arranjos quaternários, seja nos aspectos arquetípicos seja nas funções da consciência. A base quaternária inconsciente é formada por dois pares de opostos: bem $/ \mathrm{mal}$ (Jung, 1952/2011), masculino/feminino (Jung, 1916/2011). O campo da consciência é, da mesma maneira, composto por dois pares de funções opostas que se arranjam de maneira quaternária: pensamento/sentimento, sensação/ intuição (Jung, 1921/2011).

\section{Caráter compensatório do campo inconsciente}

A relação do número e da mensuração com o caráter compensatório do campo inconsciente pode ser abordado a partir de diferentes pontos de vista, dentre os quais: de maneira mais ampla, a ênfase moderna no método estatístico que negligencia modos de produzir conhecimentos embasados em aspectos qualitativos; de maneira mais específica, a relação entre a dinâmica das funções da consciência, com especializações unilaterais (função superior) e a abertura para conteúdos inconscientes emergirem (função inferior).

No primeiro caso, temos o método científico pautado na relação de causa e efeito, na quantificação de dados e no método estatístico. Em comparação com os conhecimentos produzidos no Oriente, a alquimia se caracteriza como um exemplo ocidental, anterior ao processo de matematização. A postura adotada por Jung vai nessa direção, notadamente em seus diálogos com Pauli (Jung, 1950/2011c; Meier, 1992/2011; Pauli, 1952/1996) e com o sinólogo Richard Wilhelm (Jung \& Wilhelm, 1923/2013).

No segundo caso, as díades pensamento/ sentimento (de cunho racional) e sensação/intuição (de cunho irracional) formam pares de opostos. Uma dessas funções da consciência ocupa a posição superior, sendo, geralmente, mais utilizada e especializada. Vamos supor que a função pensamento seja a superior. Nesse caso, a função sentimento será inferior, estando inconsciente. A partir da especialização e do hábito, a função superior se diferencia e o indivíduo tende a se tornar inconsciente de seus sentimentos. A partir de um processo de enantiodromia, a tendência é que ocorra uma compensação do campo inconsciente e a função inferior venha à tona, trazendo consigo conteúdos inconscientes carregados de afeto (Jung, 1921/2011).

\section{A estrutura das mandalas}

A manifestação primordial da tentativa de organização psíquica se apresenta, muitas vezes, por meio de imagens circulares ou tendendo ao círculo: as mandalas. Essas configurações constituem, antes de tudo, um problema aritmético (Jung, 1954/2011). Apesar de poderem apresentar variações e irregularidades (Jung, 1950/2011b; Silveira, 1981) - mandalas estruturadas no número dois, três, cinco, sete etc. -, essas configurações psíquicas, presentes em sonhos e em expressões artísticas, geralmente mantêm um padrão de divisões quaternárias ou de múltiplos de quatro, encontrando paralelos em símbolos da alquimia e/ou da matemática, como a quadratura circuli (Jung, 1946/2011, 1950/2011b 1954/2011).

As observações de Nise da Silveira (1981) confirmam a proposta de Jung e apontam que, geralmente, as mandalas aparecem inicialmente de maneira espontânea em estados de desorientação e de dissociação psíquica, numa tentativa de reorganização. A rigorosa ordem do sistema mandálico tenta compensar a desordem do aparelho psíquico e isso pode ocorrer por intermédio de um ponto central, uma geratriz, que tece as coordenadas de orientação. A mandala é, portanto, uma manifestação do arquétipo da ordem, o mesmo arquétipo do qual o número advém.

\section{O caráter numinoso do número}

As proposições e descobertas matemáticas mostram-se, de modo geral, permanentes. Métodos de resolução de problemas desenvolvidos pelos babilônicos há milhares de anos, por exemplo, ainda são ensinados na escola. A notação, obviamente, não é mesma de tempos tão remotos, mas o vínculo histórico permanece inegável. A história da matemática se inicia com a noção de número e de contagem, dois fatores misteriosos (Stewart, 2014), sendo tão remota a origem do número inteiro que se perde nas névoas da pré-história (Boyer, 1974).

A suposição de uma origem prática para a matemática e para o desenvolvimento dos sistemas de contagem é, comumente, a mais usual. O entalhe em bastões ou em pedaços de ossos é o modo mais antigo e imediato de expressar visivelmente a ideia de número, assim como uma das formas mais antigas de comunicar e narrar, ou seja, de "contar" algo (Burton, 2011). Como enumerar e narrar estão, muitas vezes, correlacionados, é possível supor que, ao lado das origens práticas, a matemática esteja vinculada a cerimônias religiosas (Boyer, 1974). Mesmo sendo a "ciência do bom senso" (Kasner \& Newman, 1968, p. 21), o aspecto mítico e as divindades estão vinculadas aos números e à matemática, pois esta "é abstrata e isso frequentemente soa como absoluto, universal, eterno e puro. Mais do que os 
outros tipos de conhecimento, ela tem características que associamos ao divino"3 (Koetsier \& Bergmans, 2005, p. 4, tradução nossa).

\section{A grandeza divina}

As correlações entre número e divindade não estão restritas aos tempos pré-históricos e aos ritos religiosos, sendo enfatizadas também por matemáticos modernos. Assim, no século XVIII, Carl Frederich Gauss atribuiu uma de suas descobertas não ao esforço e rigor da pesquisa, mas à graça divina (Franz, 1980/1985). Essa vinculação surgiu, de maneira ainda mais evidente, nas elaborações de Georg Cantor: a matemática transfinita e seus conceitos - infinitude, transfinitude e infinitude absoluta - foram concebidas pelo sopro de Deus em seus ouvidos, constituindo-se como produto divino e, ao mesmo tempo, como caminho para a compreensão de Deus (Krajewsky, 2016; Naylor, 2018; Recalde \& Beltrán, 2017).

\section{A relação entre a trindade e a quaternidade}

Como dissemos no início deste estudo, Jung (1940/2011) abordou o principal símbolo da fé cristã, a trindade, a partir do ponto de vista psicológico. Após apresentar paralelos entre diversas tríades divinas - na Babilônia, no Egito e na Grécia -, Jung afirma que a trindade se caracteriza, também, por seu "caráter numéricosimbólico" (p. 21). A trindade é analisada, por um lado, como resultado que advém do pensamento como uma "evolução exigida pela emancipação do espírito humano" (p. 103) e, por outro, como símbolo psicológico que se desenvolve em três etapas, cada qual relacionada a uma personificação da trindade (Pai, Filho e Espírito Santo). Nesse sentido, trata-se de um processo de "tomada de consciência" (p. 103), que não está pautado na mutação de três representações distintas, mas de uma substância única.

Assim, a trindade (Pai, Filho e Espírito Santo) é analisada em sua progressão numérica, com significados simbólicos: o Pai como a unidade primordial passa a ser questionado pela imperfeição de sua obra; a quebra da unidade possibilita o surgimento da alteridade, a díade, o mundo do Filho; com a morte do Filho, surge o terceiro elemento, o Espírito Santo. Dessa maneira, a sucessão numérica $(1,2 \mathrm{e} 3)$ corresponde ao desdobramento da divindade: "A história do dogma trinitário representa, portanto, a manifestação gradativa de um arquétipo, que organizou as representações antropomórficas" (Jung, 1940/2011, p. 57).

Na hipótese de o desdobramento numéricosimbólico se estender da trindade para a quaternidade, ou seja, para a totalidade, há que se pensar quais conteúdos e aspectos estão excluídos e podem estar potencialmente envolvidos nesse processo. A trindade cristã deixa de

3 No original: "is abstract and it often seems absolute, universal, eternal and pure. More than other kinds of knowledge it possesses charteristics that we associate with the divine". fora o feminino e o mal, representados, por exemplo, por Maria e pelo diabo. Enfim, a trindade não conta com a presença da matéria, mas apenas de aspectos espirituais. Nesse sentido, Jung (1940/2011) caracteriza o Dogma da Assunção de Maria como possibilidade do corpo ser introduzido no céu, preparando a divinização de Maria $\mathrm{e}$, ao mesmo tempo, o processo rumo à quaternidade. A transposição do corpo para o reino metafísico aponta, também, para a aproximação de outro fator negligenciado na e pela trindade cristã: o princípio corruptor (mal).

\section{O número como grandeza imprevisível entre o mito e a realidade}

Contar consiste em estabelecer relações biunívocas entre elementos (Smullyan, 1992). Esse princípio está presente em qualquer contexto que envolva o ato de contar, desde a prática primitiva de emparelhar cálculos, seixos e pauzinhos, até os modernos sistemas de contagem e de enumeração. Assim, as pessoas contam, até que nomeiam "muitos". Esse é o ponto crítico que marca uma das mais severas problemáticas da contagem: a noção de infinito. Por meio da nomeação "muitos" ocorre a percepção de que todos possuímos, mesmo que de maneira implícita, a noção de infinitude dos números naturais (Franz, 1980/1985).

Mas a noção de infinito escapa aos aspectos estritamente quantitativos do campo da matemática. Trata-se exatamente da impossibilidade de progressão da contagem. Em seus aspectos míticos, porém, a noção de infinito passa a contar com uma grandeza imprevisível. Em algumas religiões, o único ser capaz de contar infinitamente é a divindade. No Novo Testamento, por exemplo, o Deus dos grandes números, ou melhor, do infinito, é capaz de contar os cabelos de nossa cabeça (Franz, 1980/1985), como mostra o Evangelho de Lucas (XII: 6-7).

Assim, para Deus é possível o infinito, para os humanos há um limite e, a partir daí, diz-se "muitos". Alguns aborígenes da Austrália contam até dois e indígenas sul-americanos contam até seis, após chegarem a seus respectivos limites numéricos, enunciam "muitos" (Burton, 2011). Em Queensland, também na Austrália, os nativos contam "um, dois, dois e um, dois e dois, muitos" (Eves, 2011). Os exemplos se multiplicam: pigmeus africanos, nativos da Terra do Fogo, os Hotentotes. Variando o número limite, todos carregam o mesmo princípio: "muitos" pertence à divindade. Desde o momento que aprendeu a contar - um, dois, depois três, quatro, cinco e assim por diante-, até os dias de hoje, o ser humano retira, gradativamente, "um pedaço do território do senhor Deus que tudo conta" (Franz, 1980/1985, p. 31).

\section{A relação do número com os eventos sincronísticos}

A partir de intenso e prolongado debate com o físico Wolfgang Pauli (Meier, 1992/2011), Jung 
(1950/2011c) desenvolveu a hipótese da relação acausal entre fenômenos psíquicos e físicos, as denominadas coincidências significativas ou sincronicidade. A ciência ocidental moderna está pautada em fenômenos relacionados de maneira causal, ou seja, eventos em que todo efeito pressupõe uma causa. Mas, a observação de acontecimentos relacionados não pela causalidade, mas pelo significado, faz Jung criar argumentos acerca da relação entre dois fenômenos, sem que um seja a causa da outra. Esses eventos não encontram, portanto, base explicativa na causalidade e nem são casuais, dado que há impacto no indivíduo e fazem sentido, podem estar correlacionados de maneira acausal.

Jung (1950/2011c) identifica três modos que caracterizam a ocorrência de eventos sincronísticos: (1) simultaneidade entre um evento psíquico e outro físico; (2) eventos psíquico e físico próximos da simultaneidade; e (3) coincidência entre um evento psíquico e um acontecimento futuro. Nos três casos, para se falar em sincronicidade, a mínima possibilidade de uma relação causal tem que ser descartada e os fenômenos devem estar relacionados pelo significado. Como os acontecimentos estão vinculados ao fator tempo, mas não acontecem, necessariamente, de maneira sincrônica, há a opção pela criação do conceito de sincronicidade.

Os fenômenos de sincronicidade podem envolver séries numéricas e/ou estabelecer coincidências significativas com determinado número. Nos dois casos, estamos falando de aspectos qualitativos do número e da mensuração. Vamos destacar apenas um exemplo apresentado por Jung (1050/2011c): uma pessoa compra um bilhete de metrô e, em seguida, a entrada para o teatro e os dois apresentam a mesma numeração; mais tarde, recebe um telefonema e o número do aparelho do interlocutor é igual ao do bilhete e da entrada. É claro que essa sequência de três eventos que apresentam a mesma numeração não pode ser pensada em termos de causalidade, mas cria uma forte impressão na pessoa envolvida.

Os fenômenos de sincronicidade e os números estabelecem conexões, pois estão envoltos em mistério e possuem numinosidade (Jung, 1950/2011c). No exemplo apresentado, há o número tanto na série de eventos (três) quanto na coincidência significativa (a mesma numeração no bilhete de metrô, na entrada para o teatro e no número de telefone do interlocutor). Além disso, o número tem relação direta com a sincronicidade pelo fato de aparecer como propriedade da matéria e, também, como base ordenadora inconsciente. Dessa maneira, o número traz, além do evidente caráter quantitativo, características qualitativas que possibilitam seu aparecimento em eventos de coincidências entre imagens psíquicas e acontecimentos da realidade concreta, enfim, como "o elemento capaz de unificar o domínio da matéria e da

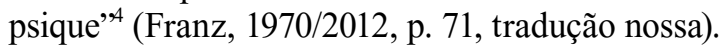

4 No original: "l'élément propre à unifier le domaine de la matière et celui de la psyché".
Retomando a relação entre o número três e o número quatro, presente em diversas observações de Jung sobre variados temas: na tipologia, há uma função inferior (Jung, 1921/2011); a trindade cristã não integra o elemento feminino (Jung, 1940/2011); e nos diálogos entre Jung e Pauli (Meier, 1992/2011), a hipótese da sincronicidade é elaborada como o quarto elemento que se integra à tríade espaço, tempo e matéria, formando um quatérnio com dois pares de opostos: energia indestrutível/contínuo espaço-tempo; conexão constante pelo efeito (causalidade)/conexão inconstante por meio da contingência ou da equivalência ou "significação" (sincronicidade) (Jung, 1950/2011c).

\section{O número como arquétipo da ordem que se tornou consciente}

A partir das concepções da Psicologia Analítica, podemos dizer que a contagem de $\mathrm{N}$, ou seja, de tudo, do infinito, é uma atividade inerente ao Si-mesmo. Assim, a ordem está no mundo e podemos contar a população de uma cidade, as maçãs de uma árvore, as árvores de um jardim e, quem sabe, os fios de cabelo. Mas a ordem também está implícita em cada um de nós, possuindo uma base arquetípica (Jung, 1940/2011, 1950/2011a, 1954/2011).

Para Jung (1954/2011), a formulação do conhecimento é uma ordenação e, quando possível, se manifesta por sequências numéricas apreendendo algum dado sobre a natureza das coisas. Esse ordenamento não se limita a um simples enumerar, mas insere o sujeito na relação de reproduzir e apreender a ordem no mundo, implicando, também, em aspectos qualitativos da enumeração na formulação do conhecimento. Conhecer é, portanto, uma formulação psicofísica mediada por um recurso psicoide, a saber, o número, e aí jaz seu aspecto psicofísico: a possibilidade de se manifestar fisicamente nos padrões da natureza e psiquicamente nos fenômenos mentais (Jung, 1950/2011c).

A coincidência entre um fato objetivo e uma imagem mental pressupõe conexões entre a mente do sujeito e o mundo material. É, portanto, o genuíno encontro entre psique e matéria, como se o funcionamento do mundo e o do psiquismo passassem a caminhar em consonância tocando uma única melodia - a melodia do conhecimento formulado (Pauli, 1952/1996). Esse conhecimento pode ser uma complexa equação de movimento, a determinação da cardinalidade conjunta ou a narrativa descritiva de um evento que ordena fenômenos em uma linha temporal. Essa última ideia pode parecer estranha à primeira vista, mas é de fácil compreensão.

A filologia comparada nos permite perceber o elo entre número e narrativa por via da ordenação. Quando um cientista relata um fato observado, ele nos "conta" algo, a versão inglesa desse verbo é to tell (narrar ou contar uma história ou evento) que corresponde ao alemão erzhäle, que deriva do substantivo Zahl (número), vinculado também a erzählen (enumerar). Há, aí, um princípio arquetípico, ou seja, uma intuição matemática 
primordial, pois Erzähler (enumerador, se traduzido ao pé da letra) é o narrador, o contista, enquanto Erzählung é uma narrativa, um relato. Em francês, o verbo to tell se transforma em raconter, relacionado ao verbo compter (contar ou enumerar), advindo do latino computare (Franz, 1980/1985). Fenômeno semelhante acontece em português. Quando se usa o verbo "contar", é possível se referir a um conjunto estático ou à ordenação dos fatos no tempo, estamos nos referindo invariavelmente a uma ordenação psicoide. Esse fenômeno linguístico não é restrito aos idiomas do Ocidente. Em chinês e japonês, há o seguinte ideograma: 契 - lê-se chigiri na língua nipônica. Trata-se de um kanji composto por três caracteres: o primeiro, superior esquerdo, representa uma talha com entalhes e é também a forma arcaica de expressar o número três (san, em japonês) e, de modo geral, expressa a ideia de contagem; o segundo, superior direito, representa uma faca ou lâmina (lê-se em japonês, $h \bar{a})$; o último, em baixo, significa grande (lê-se $\bar{o}$ ). Um contrato ou acordo, em japonês, é etimologicamente "uma talha com grandes entalhes", o registro narrativo de um acordo, ou melhor, o contar de um acordo (Almeida, 2013).

Esses exemplos evidenciam que a noção de paridade um a um sustenta e origina todo tipo de comunicação mais complexa, seja aritmética ou narrativa, folclórica ou científica. A humanidade deve ter notado em algum momento que, quando narra uma história, é como se estivesse contando, ordenando eventos no tempo, obedecendo assim o ritmo predeterminado dos fatos, o pulsar físico da natureza (Franz, 1980/1985). Todo esse processo harmônico entre psique e matéria fundamenta-se em uma imagem arquetípica, a do herói que desbrava o desconhecido e apreende os ritmos da natureza conquistando cada vez mais espaço no jogo do qual apenas Deus, inicialmente, sabia as regras.

Ao enumerar, mensurar ou dispor formas geométricas, o ser humano ordena os fenômenos. O número é, assim, um produto do espírito humano e, como tal, carrega uma série de aspectos simbólicos. Atualmente, lidamos com os números de maneira cotidiana: ao elaborarmos uma lista de compras, quando temos de pagar uma conta, na anotação de uma receita, no interesse pelo tempo de posse de bola de um time de futebol, na diferença de milésimos de segundos estabelecida por um novo recorde mundial ou, quem sabe, quando contamos carneirinhos. Esses exemplos banais apontam para a conclusão de que o número é, enfim, o "arquétipo da ordem que se tornou consciente" (Jung, 1950/2011c, p. 51).

\section{As intuições primordiais}

Como visto até aqui, o número é uma unidade fundamental do psiquismo humano. Assim, qualquer fenômeno confrontado pelo homem o terá como principal mediador do processo. Contar algo é uma forma de assimilar os eventos e o caminho mais elementar para fazê-lo é por meio dos números naturais. São chamados naturais, pois são justamente aqueles utilizados para contar. A sequência de ícones 1, 2, 3, 4, 5, 6, 7, 8 e 9 são os signos, representações que compõem todo o conjunto dos possíveis sistemas de organização da cognição em torno da faculdade elementar de ordenação e contagem (Mendes, 2006).

\section{A série infinita dos números naturais}

Esse contínuo ou sequência de números que tende ao infinito pode ser representado de diversos modos. Oralmente, esses números são evocados através dos nomes um, dois, três, quatro etc., que representam as categorias (ou números) mais baixas da série até um limite evidentemente determinado pelos recursos das linguagens locais. É válido lembrar, todavia, que esses recursos podem ser incrementados conforme a necessidade. Independentemente do idioma, tais palavras são quase sempre diferenciadas e autônomas em relação ao sistema lexical. De modo geral, as crianças se familiarizam pela primeira vez com tais termos por meio de uma atividade de cálculo simbólico, presente geralmente em narrativas ou trovas rimadas (Mendes, 2006).

A partir das rimas ou de jogos numéricos, a capacidade de contar deve se desenvolver, posteriormente, em relação ao ambiente e aos eventos do meio. A numeração é o ato intelectual mais arcaico e, para operá-lo, é necessário estabelecer um referencial sobre o qual será concebido e desenvolvido um sistema numérico (Mendes, 2006).

Toda a teoria que embasa esse sistema referencial deriva dos três axiomas básicos de Peano. Para entendermos matematicamente a construção da série dos números naturais, temos que pensá-los como elementos não definidos. Tomemos um conjunto $\mathbb{N}$, cujos elementos chamaremos de números naturais. Recorreremos, então, a uma função $s: \mathbb{N} \rightarrow \mathbb{N}$. Para todo $n \in \mathbb{N}$, o número $s(n)$, valor que a função $S$ assume no ponto $n$, será entendido como sucessor de $\boldsymbol{n}$. Assim, a função deverá satisfazer os seguintes axiomas enunciados por Peano: (I) $S: \mathbb{N} \rightarrow \mathbb{N}$ é injetiva. Ou seja, $m, n \in \mathbb{N}, s(m)=s(n) \Rightarrow m=n$. Em português claro, dizemos que dois números que têm o mesmo sucessor são iguais. (II) $\mathbb{N}-S(\mathbb{N})$ conta de um único elemento. Isto é, há um número natural apenas que não seja sucessor de nenhum outro, ele é denominado de "um" e representado pelo signo 1. (III) $S e X \subset \mathbb{N}$ é um subconjunto tal que $1 \in X$ e, para todo $n \in X$ há também $s(n) \in X, \log o X=\mathbb{N}$. Este último, denominado de Princípio da Indução, pode ser enunciado verbalmente da seguinte maneira: seja $\alpha$ uma propriedade dos números naturais; se 1 tem tal propriedade e se, de fato, outro número natural $p$ tiver a propriedade $\alpha$ for possível concluir que $p+1$ gozará também da propriedade $\alpha$, logo todos os números naturais terão essa propriedade (Lima, 2009).

Esses três axiomas dão vida ao simples processo de contar os números um após o outro. E é justamente essa perene presença de um sucessor o que garante a existência de uma série infinita dos números naturais. 
E, desse mero ato de contar, derivam diversos outros eventos de maior ou menor complexidade, um deles é a Matemática Animal, um fenômeno bastante peculiar que diz sobre a capacidade dos animais perceberem e até mesmo operarem em dispositivos matemáticos numéricos ou geométricos. Trata-se de um tipo especial de matemática não verbal e inata (Almeida, 2013). Diversas espécies do reino animal gozam desse tipo de percepção numérica. Sabe-se, por enquanto, que dentre elas estão os primatas - incluindo os humanos (Dehaene, 2005) -, insetos (Nieder, 2018), peixes (Matsuura, 2014) e mesmo salamandras (Krusche, Uller, \& Dicke, 2010).

\section{A ideia de continuum}

O conjunto de dados evidenciados pela matemática animal são assustadores, pois nos mostram que aqueles axiomas fundamentais de Peano, brevemente enunciados anteriormente, estão vivos e operantes não apenas em humanos, mas também em diversos animais. Obviamente, a matemática animal tem suas limitações. Quando contam, os animais o fazem em proporção reduzida. Os humanos, já dotados de uma matemática cognitiva e simbólica, vão um pouco além: alguns contam até cinco, outros até seis, até dez, doze ou até números gigantescos. Como apontamos, essa quantia varia conforme costumes e necessidades étnico-culturais (Almeida, 2013).

Mas o que aconteceria se esse contínuo de números naturais fosse explorado até o seu fim? Foi aproximadamente essa a pergunta elaborada por Georg Cantor. O "matemático dos infinitos" desenvolveu diversos artifícios matemáticos que o permitiu ultrapassar os limites da contagem. Em resumo, Cantor contou até o infinito não bastar e, então, saltou para o transfinito. E, nessa nova dimensão, o que ele descobriu foi a existência de um novo contínuo, que o levou a elaborar a hipótese do continuum. Cantor, evidentemente, não chegou ao último número da série infinita dos números naturais, pois ela é infinita. Por meio de comparação entre conjuntos, o matemático percebeu que existiam infinitos de diversos tamanhos e levantou a hipótese de que esses infinitos se organizavam em uma nova série: a série transfinita (Vale, 2018).
O que nos importa neste estudo é o significado psicológico desvelado pela hipótese e pela ideia de um continuum transfinito. Cantor contou até o infinito e para além dele, tangenciou o Deus que tudo conta. A matemática de Cantor, quando explicada por ele mesmo, é repleta de alusões divinas e figuras de caráter arquetípico. Quando se fala em uma contagem que vai para além das finitudes, fala-se de um contato direto com o Si-mesmo, arquétipo da ordem de tudo o que jaz no psiquismo (Vale, 2018).

Sendo o ponto gênico do psiquismo, a instância arquetíicica fundamental e o manancial de libido, o Si-mesmo não pode ser assimilado pelo campo da consciência em sua totalidade. Assim, a cada nova assimilação de conteúdos inconscientes, abre-se um novo infinito de possibilidades, uma nova série ou um novo continuum (Neumann, 1949/1995). Dessa maneira, mesmo que um matemático salte para instâncias dos infinitos, ainda haverá uma nova série infinita de infinitos para percorrer e o número, enquanto realidade arquetípica e numinosa, demonstrará sua fatal irredutibilidade (Vale, 2018).

\section{Considerações finais}

Ao analisarmos um amplo espectro de concepções do número e da mensuração em seus aspectos quantitativos, qualitativos e como intuição matemática primordial, desenvolvemos um estudo de cunho exploratório (Minayo, 2009). O eixo central se encontra em levantar, ao longo da obra de Jung, os diversos aspectos do número. Esse levantamento possibilita o aprofundamento de cada um dos tópicos apresentados e as análises cruzadas entre vários desses aspectos. Podemos considerar que o número e a mensuração estiveram presentes nos diversos trabalhos desenvolvidos por Jung, desde o teste de associação de palavras até a elaboração da hipótese da sincronicidade. Por vezes, prevalece o aspecto quantitativo; em outras ocasiões, o aspecto qualitativo se mostra mais importante. Fica evidente, neste trabalho, que Jung enfatiza os aspectos qualitativos do número e da mensuração. E, mais ainda, a exploração psicológica sobre o tema aponta para a base arquetípica do número como fator de ordenação e de articulação entre psique e matéria.

\section{Primordial mathematical intuitions}

Abstract: This article presents an exploratory study on the quantitative and qualitative aspects of the number in Jung's work. Thus, aspects of the number were surveyed, from the word association tests to the concept of synchronicity. The article was divided into three parts: presentation of quantitative aspects (reaction time in the word association test; and concept of psychic energy); presentation of qualitative aspects (number as psychic content; number as an organizing element of the psyche; numinous character of number; number as unpredictable greatness between myth and reality; the relationship of number to synchronistic events; and number as an archetype of the order that has become conscious); and presentation of primordial mathematical intuitions (the infinite series of natural numbers; and the idea of a continuum). By emphasizing the qualitative aspects, Jung points to the archetypal base of the number as a factor of ordering and articulation between psyche and matter.

Keywords: C. G. Jung, analytical psychology, number, archetype. 


\section{Les intuitions mathématiques primordiales}

Résumé : Cet article présente une étude exploratoire sur les aspects quantitatifs et qualitatifs du nombre dans l'œuvre de Jung. On a réalisé une enquête sur les aspects du nombre, des tests d'association de mots au concept de synchronicité. L'article est divisé en trois parties : présentation des aspects quantitatifs (temps de réaction dans le test d'association de mots et concept d'énergie psychique) ; présentation des aspects qualitatifs (le nombre en tant que contenu psychique et élément organisateur de la psyché ; le caractère numineux du nombre ; le nombre en tant que grandeur imprévisible entre mythe et réalité ; la relation du nombre avec les événements synchrones ; et le nombre en tant qu'archétype de l'ordre devenu conscient) ; et présentation des intuitions mathématiques primordiales (la série infinie de nombres naturels et l'idée de continuum). En mettant l'accent sur les aspects qualitatifs, Jung souligne la base archétypale du nombre en tant que facteur d'ordre et d'articulation entre la psyché et la matière.

Mots-clés : C. G. Jung, psychologie analytique, nombre, archétype.

\section{Intuiciones Matemáticas Primordiales}

Resumen: Este artículo hace un estudio exploratorio sobre los aspectos cuantitativos y cualitativos del número en la obra de Jung. Se examina aspectos del número desde pruebas de asociación de palabras hasta el concepto de sincronicidad. El artículo se divide en tres partes: presentación de aspectos cuantitativos (tiempo de reacción en la prueba de asociación de palabras y concepto de energía psíquica); presentación de aspectos cualitativos (número como contenido psíquico, número como elemento organizador de la psique, carácter numinoso del número, número como grandeza impredecible entre mito y realidad, relación del número con eventos sincronísticos, y número como arquetipo del orden en que se ha convertido consciente); y presentación de intuiciones matemáticas primordiales (la serie infinita de números naturales y la idea de un continuo). Al enfatizar los aspectos cualitativos, Jung señala la base arquetípica del número como un factor de orden y articulación entre la psique y la materia.

Palabras clave: C. G. Jung, psicología analítica, número, arquetipo.

\section{Referências}

Almeida, M. (2013). O nascimento da matemática: a neurofisiologia e a pré-história da matemática. São Paulo, SP: Livraria da Física.

Bishop, P. (2007). Analytical psychology and German classical aesthetics: Goethe, Schiller and Jung (Vol. 1). New York: Routledge.

Boyer, C. (1974). História da matemática. São Paulo, SP: Edgard Blücher.

Burton, D. M. (2011). The history of mathematics: an introduction. New York: McGrall Hill.

Dehaene, S. (2005). How a primate brain comes to know some mathematical truths. In J. P. Changeux, A. R. Damasio, W. Singer, \& Y. Christen (Orgs.), Neurobiology of human values: research and perspectives in neurosciences (pp. 143-155). Berlim: Springer. doi: 10.1007/3-54029803-7_12

Duarte, L. F. D. (1999). Método e ficção nas ciências humanas: por um universalismo romântico. In A. M. Jacó-Vilela, F. Jabur, \& H. B. C. Rodrigues (Orgs.), Clio-Psyché: histórias da psicologia no Brasil (pp. 53-64). Rio de Janeiro, RJ: UERJ.

Eves, H. (2011). Introdução à história da matemática. Campinas, SP: Unicamp.
Ferreira, A. C., \& Silveira, L. H. L. (2015). Do Círculo de Eranos à construção do simbólico, em Carl Gustav Jung. Psicologia USP, 26(2), 259-268. doi: 10.1590/0103656420140002

Feyerabend, P. (2011). Contra o método. São Paulo, SP: Unesp. (Trabalho original publicado em 1975)

Figueiredo, L. C. M. (2015). Revisitando as psicologias: da epistemologia à ética das práticas e discursos psicológicos. Petrópolis, RJ: Vozes.

Franz, M.-L. (1985). Adivinhação e sincronicidade: a psicologia da probabilidade estatística. São Paulo, SP: Cultrix. (Trabalho original publicado em 1980)

Franz, M.-L. (2012). Nombre et temps: psychologie des profondeurs et physique moderne. Paris: Pierre de la Fontaine. (Trabalho original publicado em 1970)

Hewitt, P. G. (2011). Física conceitual. Porto Alegre, RS: Bookman.

Jaffé, A. (1989). O mito do significado na obra de C.G. Jung. São Paulo, SP: Cultrix.

Jung, C. G. (2008). Chegando ao inconsciente. In C. G. Jung (Org.), O homem e seus Símbolos (pp. 15-131). Rio de Janeiro, RJ: Nova Fronteira. (Trabalho original publicado em 1961) 
Jung, C. G. (2011). O tempo de reação nos experimentos de associações. In Estudos experimentais (Vol. 2, pp. 249-306). Petrópolis, RJ: Vozes. (Trabalho original publicado em 1905)

Jung, C. G. (2011). Contribuição ao conhecimento dos sonhos com números. In Freud e a psicanálise (Vol. 4, pp. 59-67). Petrópolis, RJ: Vozes. (Trabalho original publicado em 1910)

Jung, C. G. (2011). Psicologia do inconsciente (Vol. 7/1). Petrópolis, RJ: Vozes. (Trabalho original publicado em 1916)

Jung, C. G. (2011). Tipos psicológicos (Vol. 6). Petrópolis, RJ: Vozes. (Trabalho original publicado em 1921)

Jung, C. G. (2011). A energia psíquica (Vol. 8/1). Petrópolis, RJ: Vozes. (Trabalho original publicado em 1928)

Jung, C. G. (2011). Princípios básicos da prática da psicoterapia. In A prática da psicoterapia (Vol. 16/1, pp. 13-31). Petrópolis, RJ: Vozes. (Trabalho original publicado em 1935)

Jung, C. G. (2011). Psicologia e religião(Vol. 11/1). Petrópolis, RJ: Vozes. (Trabalho original publicado em 1939)

Jung, C. G. (2011). Interpretação psicológica do dogma da trindade (Vol. 11/2). Petrópolis, RJ: Vozes. (Trabalho original publicado em 1940)

Jung, C. G. (2011). Psicologia e alquimia (Vol. 12). Petrópolis, RJ: Vozes. (Trabalho original publicado em 1944)

Jung, C. G. (2011). Considerações teóricas sobre a natureza do psíquico. In A natureza da psique (Vol. 8/2, pp. 104-185). Petrópolis, RJ: Vozes. (Trabalho original publicado em 1946)

Jung, C. G. (2011a). Aion: estudo sobre o simbolismo do Si-mesmo (Vol. 9/2). Petrópolis, RJ: Vozes. (Trabalho original publicado em 1950)

Jung, C. G. (2011b). O simbolismo da mandala. In Os arquétipos e o inconsciente coletivo (Vol. 9/1, pp. 359-392). Petrópolis, RJ: Vozes. (Trabalho original publicado em 1950)

Jung, C. G. (2011c). Sincronicidade (Vol. 8/3). Petrópolis, RJ: Vozes. (Trabalho original publicado em 1950)

Jung, C. G. (2011). Resposta a Jó (Vol. 11/4). Petrópolis, RJ: Vozes. (Trabalho original publicado em 1952).

Jung, C. G. (2011). Um mito moderno sobre coisas vistas no céu (Vol. 10/4). Petrópolis, RJ: Vozes. (Trabalho original publicado em 1954)

Jung, C. G. (2011). Estudos experimentais (Vol. 2). Petrópolis, RJ: Vozes. (Trabalho original publicado em 1979)

Jung, C. G., \& Wilhelm, R. (2013). O segredo da flor de ouro: um livro de vida chinês. Petrópolis, RJ: Vozes. (Trabalho original publicado em 1923)

Kasner, E., \& Newman, J. (1968). Matemática e imaginação. Rio de Janeiro, RJ: Zahar.

Koetsier, T., \& Bergmans, L. (2005). Introduction. In T. Koetsier \& L. Bergmans (Orgs.), Mathematics and the divines (pp. 1-46). Amsterdam: Elsevier.

Krajewsky, S. (2016). Theological metaphors in mathematics. Studies in Logic, Grammar and Rhetoric, 44(57), 13-30. doi: $10.1515 /$ slgr-2016-0002

Krusche, P., Uller, C., \& Dicke, U. (2010). Quantity discrimination in salamanders. The Journal of Experimental Biology, (213), 1822-1828. doi: 10.1242/jeb.039297
Kuhn, T. (2007). A estrutura das revoluções cientificas. São Paulo, SP: Perspectiva. (Trabalho original publicado em 1962)

Lima, E. L. (2009). Curso de análise (Vol. 1). Rio de Janeiro, RJ: Instituto Nacional de Matemática Pura e Aplicada.

Matsuura, K. (2014). A new pufferfish of the genus Torquigener that builds «mystery circles» on sandy bottoms in the Ryukyu Islands, Japan. Ichthyologica Research, 62, 207-212. doi: 10.1007/s10228-014-0428-5

Meier, C. A. (2011). Atom and archetype: Pauli/Jung letters - 1932-1958. London: Routledge. (Trabalho original publicado em 1992)

Melo, W. (2015). O interesse de Jung pelos fenômenos anômalos: concepções do campo científico e implicações pedagógicas. In W. Melo, P. H. C. Resende, S. Silveira, V. F. Henriques, \& E. A. F. Souza (Orgs.), A liberdade ainda que tardia (pp. 90-103). Rio de Janeiro, RJ: Espaço Artaud.

Melo, W. (2019). O grupo caminhos junguianos como uma experiência de pesquisa e ensino-aprendizagem em psicologia analítica. In F. Kyrillos Neto \& W. Melo (Orgs.), Psicologia e subjetividade: fundamentos conceituais e métodos de pesquisa (pp.87-102). Belo Horizonte, MG: EdUEMG.

Mendes, I. A. (2006). Números: o simbólico e o racional na história. São Paulo, SP: Livraria da Física.

Miller, A. I. (2009). Deciphering the cosmic number: the strange friendship of Wolfgang Pauli and Carl Jung. New York: Norton \& Company.

Minayo, M. C. S. (Org.). (2009). Pesquisa social: teoria, método e criatividade. Petrópolis, RJ: Vozes.

Naylor, M. (2018). God, envil and infinity value. Religions, 9(1), 1-11. doi: 10.3390/re19010020

Neumann, E. (1995). The origens and history of counciousness. New York: Princeton University Press. (Trabalho original publicado em 1949)

Nieder, A. (2018). Honey bees zero on the empty set. Science, 360(6393), 1069-1070. doi: 10.1126/science.aat 8958

Pauli, W. (1996). La influencia de las ideias arquetípicas em las teorias científicas de Kepler. In W. Pauli, Escritos sobre física y filosofia (pp. 277-353). Madri: Debate. (Trabalho original publicado em 1952)

Pauli, W. (1999). Aspects scientifiques et épistémologiques des idées concernant l'inconscient. In W. Pauli, Physique moderne et philosophie (pp. 179-198). Paris: Albin Michel. (Trabalho original publicado em 1955)

Peterson, F., \& Jung, C. G. (2011). Investigações psicofísicas com o galvanômetro e o pneumógrafo em pessoas normais e doentes mentais. In C. G. Jung, Estudos experimentais (Vol. 2, pp. 543-607). Petrópolis, RJ: Vozes. (Trabalho original publicado em 1907)

Piacentini, J. J., Grandi, B. C. S., Hofmann, M. P., Lima, F. R. R., \& Zimmermann, E. (2008). Introdução ao laboratório de fisica. Florianópolis, SC: UFSC.

Quaglino, G. P., Romano, A., \& Bernardini, R. (2007). Carl Gustav Jung a Eranos: 1933-1952. Turin: Antigone.

Recalde, L. C., \& Beltrán, A. C. (2017). Algunas disquisiciones filosóficas en torno al problema de la 
existência del infinito em matemáticas. Praxis Filosófica, (45), 219-241. doi: 10.25100/pfilosófica/v0i45S.6147

Ricksher, C., \& Jung, C. G. (2011). Pesquisas adicionais sobre o fenômeno galvânico, pneumográfico e a respiração em pessoas normais e doentes mentais. In C. G. Jung, Estudos experimentais (Vol. 2, pp. 608-636). Petrópolis, RJ: Vozes, 2011. (Trabalho original publicado em 1907)

Silveira, N. (1981). Imagens do inconsciente. Rio de Janeiro, RJ: Alhambra.

Smullyan, R. (1992). Cantor's fundamental discovery. In R. Smullyan, Satan, Cantor and infinity and others mindboggling puzzles (pp. 219-231). New York: Alfred A. Knopf.

Stewart, I. (2014). Em busca do infinito: uma história da matemática dos primeiros números à teoria do caos. Rio de Janeiro, RJ: Zahar.
Vale, P. R. B. R. (2018). Psicologia do número infinito: as imagens arquetípicas na matemática transfinita de Georg Cantor (Dissertação de mestrado). Universidade Federal de São João del-Rei, São João del-Rei, MG.

Vale, P. R. B. R., \& Melo, W. (2019). Psicologia do número: uma análise junguiana do número e do processo de contagem. Pesquisas e Práticas Psicossociais, 14(4), 1-13.

Wahba,L.L.(2019). Acriaçãode sensibilidades: epistemologia e método na psicologia analítica. Psicologia: Teoria e Pesquisa, 35, 1-7. doi: 10.1590/0102.3772e3548

Recebido: 10/12/2020

Revisado: 08/03/2021

Aprovado: 28/03/2021 